Stem cell

\section{differentiation and the effects of deficiency}

HS Dua', A Joseph', VA Shanmuganathan ${ }^{1}$ and RE Jones ${ }^{2}$

\begin{abstract}
Stem cells have several unique attributes, the key features being their potency and plasticity. They have the ability to give rise to multiple cell lineages and to transdifferentiate into totally different cell type(s) when relocated to a novel stem cell niche. Most self-renewing tissues are served by stem cells. At the ocular surface, the corneo-scleral limbus is believed to provide the niche for corneal epithelial stem cells. A large body of circumstantial evidence, both clinical and basic, supports this view. However, specific identification of limbal stem cells has proved elusive. Cytokeratin markers, vimentin, epidermal growth factor receptors, p63, and others have been used to identify epithelial cell populations at the limbus, which could harbour putative stem cells. In contrast, none of the known haematopoietic stem cell markers namely, CD34 and CD133, stain any specific subset of corneal or limbal epithelial cells. Singly or collectively, none of these markers point to any unique cell(s) that could be regarded as stem cells, supporting the notion that the corneal epithelium is served by 'committed progenitors' rather than by stem cells. Disease or destruction of the corneoscleral limbus is associated with consequential events that eventually lead to visual impairment or blindness. Conjunctivalisation and vascularisation of the corneal surface and persistent or recurring epithelial defects are hallmarks of limbal deficiency. Eye (2003) 17, 877-885. doi:10.1038/

sj.eye. 6700573
\end{abstract}

Keywords: stem cell; corneo-scleral limbus; epithelium; p63; CD34; CD133

A single all encompassing definition of stem cells (SC) is not easy to provide. There are several attributes, which when demonstrated by a cell, in their entirety or in a significant proportion, would enable the cell to be classed as an SC. SC are undifferentiated or poorly differentiated and usually do not exhibit the functional characteristics of their progeny. They are slow cycling but highly clonogenic with a great potential for error-free division. They are a self-renewing population of cells that can proliferate indefinitely ${ }^{1}$ and survive for the duration of the organ(ism) in which they reside. Self-renewal is brought about by asymmetric cell division whereby one daughter cell stays back in the SC niche and the other follows the path of proliferation and differentiation, acquiring functional characteristics of the tissue or organ. The same balance can be maintained by other strategies of cell division and differentiation. SC usually are confined to their 'niche', which is a specific location within the organ where the microenvironment supports and maintains the stemness of SC and affords a degree of protection. In solid organs, where cell migration commences at one point and progresses until the cells are shed at a distant point(s), the SC niche is usually located at the point of commencement. SC constitute only a small proportion of the total cell population that they sustain. This can range from $0.01 \%$ (haematopoietic SC) to 10\% (epidermal SC), although the latter figure may be an overestimation. ${ }^{2,3}$

One of the major attributes of SC is their potential to give rise to different cell lineages. This potency is however not equal among all SC and there exists among SC a hierarchy of potential. SC can be totipotent, pluripotent, multipotent, or unipotent. The zygote that can form the entire embryo and part of the placenta is an example of a totipotent cell. Cells of the inner cell mass from which most cells that arise from the three germ layers can be derived, but not components of the placenta, are considered pluripotent. Most tissue-specific SC are multipotent, capable of producing lineages that can differentiate in two, three, or more different cell types with functional attributes of the organ in which they reside. For example, in the small
${ }^{1}$ Division of Ophthalmology and Visual Sciences School of Clinical Laboratory Sciences University of Nottingham Nottingham, UK

${ }^{2}$ Division of Molecular and Clinical Immunology School of Clinical Laboratory Sciences University of Nottingham Nottingham, UK

Correspondence: HS Dua

Department of Ophthalmology B Floor, Eye \& ENT centre University Hospital Queen's Medical Centre Nottingham NG7 2UH, UK Tel: + 44 (0)1159709796 Fax: + 44 (0)1159709963 E-mail: harminder.dua@ nottingham.ac.uk

Received: 28 February 2003 Accepted in revised form: 28 February 2003 
intestine, the Paneth cells, goblet cells, absorptive, and enteroendocrine cells all originate from common SC. Some SC may have only limited potential with the ability to generate only one specific cell type. These SC are labelled unipotent SC or committed progenitors. SC of the epidermis and the corneo-scleral limbus would fall into this category.

Linked to the 'potential' of SC is another unique attribute, their 'plasticity' or ability to transdifferentiate. Some SC when relocated to a different site (tissue) can assume the role that is more conducive to the structure and function of the new site. This could range from that of SC of that new site, providing cell lineages that they would not normally produce in their natural physiological location; or redifferentiate into cells that are natural to the new site, thus aiding in regeneration, repair, and maintenance of the cell population at the new site. Only a small number of redifferentiated cells could re-create the environment required to rescue or support the native cells of the new location. Using in situ hybridisation for $\mathrm{Y}$ chromosome, green fluorescent protein tracking, and techniques detecting unique enzymes or proteins of donor cells, evidence in support of SC plasticity has been provided in bone marrow (both haematopoietic and mesenchymal), pancreatic, and neuronal cells. ${ }^{4} \mathrm{SC}$ potential and plasticity are both more pronounced in embryonic SC compared to adult SC. Embryonic SC have virtually an unlimited potential for self-renewal and differentiation. Given the right microenvironment and the right signals, adult and embryonic SC can (theoretically) be made to follow a desired path of differentiation or propagated indefinitely, in an undifferentiated state. ${ }^{5}$

The microenvironment, in which SC reside and maintain their stemness, is referred to as the SC niche. The niche is usually but not necessarily an anatomically defined site. In the hair follicle for instance, the bulge region that lies adjacent to the arretor pili muscle ${ }^{3}$ is considered to be the repository of SC. SC activity is influenced by both cells (niche cells) and extracellular matrix components of the niche. The niche also affords protection to the all-important SC. In the intestinal mucosa for example, it is believed that the pericryptal fibroblasts/subepithelial myofibroblasts may serve as niche cells, ${ }^{6}$ and in the epidermis, beta 1 integrinmediated adhesion to its ligand, type IV collagen, is shown to influence behaviour of epidermal SC. ${ }^{3}$ SC progeny migrate out from the niche and follow a path of differentiation. New genes are expressed with acquisition of differentiation markers. Previously expressed genes are suppressed as the cell loses its SC characteristics and acquires functional attributes of the tissue or organ in which it resides. After a finite number of replications, cells enter terminal differentiation. The immediate progeny of SC that step outside the niche have the potential to proliferate rapidly and provide the capacity for rapid expansion of the cell numbers in case of need. These cells are referred to as transient amplifying cells (TAC). In the cornea, these represent the basal cells of the peripheral and central cornea. A small proportion of these cells (perhaps cells from the first division of SC) may have the ability to revert into the SC pool. These have been referred to as transient cells (TC). TAC differentiate into postmitotic cells (PMC) and in the cornea correspond to the suprabasal wing cells of the epithelium. PMC mature into terminally differentiated cells (TDC) corresponding to the superficial cells of the corneal epithelium, which eventually desquamate.

Identification of SC (or putative SC) is currently based on several markers that are unique to SC of different specific locations. The most progress with regard to SC identification has been in the bone marrow. In haematopoietic cells, CD34, a sialomucin cell surface antigen, is considered to be a marker for SC. It is however not unique to haematopoietic cells, as small vessel endothelial cells and embryonic fibroblasts also demonstrate this protein. ${ }^{7}$ Recently, we have demonstrated its presence in stromal keratocytes of the human cornea. ${ }^{8}$ CD133, a transmembrane glycoprotein, is also a marker of haematopoietic SC. ${ }^{9,10}$ In the epidermis, SC are believed to be among the beta 1 integrin-positive population of cells. ${ }^{11}$ Nestin, an intermediate filament, has been proposed as a marker of neural SC (and TAC). ${ }^{12}$ Another RNA-binding protein known as Musashi 1 also has a similar staining pattern. ${ }^{13}$ In the intestine, like the cornea, direct markers for SC are not available, but regeneration of all cell lineages from a common SC has been demonstrated. ${ }^{14}$ SC are also believed to have developed efflux pumps using ATPbinding membrane transport proteins, which exclude toxic substances. This characteristic has been used to sort cells that exclude certain dyes (Hoechst 33342 and Rhodamine 123) and appear as the 'side population' on fluorescein-activated cell sorting (FACS) analysis. ${ }^{15}$ The ultimate proof of the SC nature of all cells isolated by using any of the markers or other means is the ability of isolated cells to form clones or colony forming units.

As a self-renewing population of cells, it is only natural that the corneal epithelium is expected to have an SC pool that serves as the source of such self-renewal. In 1983, Thoft and Friend ${ }^{16}$ proposed the $X+Y=Z$ hypothesis where $X$ represents the centripetal migration of corneal epithelial cells from the limbus, $Y$ the anteroposterior movement of cells, and $Z$ the cell loss at the surface. For the corneal epithelium to maintain a constant cell mass, the sum of $X$ and $Y$ must equal $Z$. 
There is considerable circumstantial evidence to substantiate the notion that the corneo-scleral limbus is the site or 'niche' for corneal epithelial SC. Despite the abundance of clinical and laboratory evidence pointing to the limbus as the source of corneal epithelial selfrenewal, a definitive identification of corneal epithelial SC has not been possible.

\section{Clinical evidence for limbal location of putative corneal epithelial SC}

The palisades of Vogt and the interpalisade rete ridges provide a unique structure to the limbus. The structure of the palisades and the rete ridges, their vascularity and pigmentation are all analogous to repositories of SC in the monkey palm epidermis. ${ }^{17-19}$ Several studies have indicated that migration of cells occurs in a centripetal manner from the limbus towards the centre of the cornea, not only in wound healing, but also during normal replicative epithelial turnover. This unidirectional movement from the limbus to the centre of the cornea points to the presence of a 'driving force' at the limbus. Evidence for this centripetal migration comes from early observations, in experimental animals, of traumainduced displacement and migration of limbal pigment onto clear cornea ${ }^{20,21}$ and the radial arrangement of cells following pin prick injuries to frog corneas. ${ }^{21}$ Further evidence is provided by the observation of movement of epithelial microcysts from the suture line onto donor cornea and replacement of sex chromatin of donor cornea by that of host cornea following corneal grafting. ${ }^{22,23}$ More direct evidence was provided by demonstrating the centripetal migration of limbal cells marked by India ink. $^{24,25}$ Buck $^{25}$ has reported the observation that hemidesmosomes of peripheral cells of normal and healing mouse corneas are arranged in radial rows, and interpreted this orientation to represent centripetal migration of epithelial cells.

Migration of limbal pigment onto central cornea during healing of corneal abrasions has also been reported in humans. ${ }^{26}$ Large corneal epithelial wounds, where the wound edge is closer to the limbus, heal at a faster rate than smaller wounds. ${ }^{27}$ Repeated denudation of the central corneal epithelium shows that the healing rate of the second wound is more rapid than that of the first. This suggests that rapidly dividing younger cells of the periphery have moved to more central areas after the first trauma and respond readily to the second. ${ }^{28}$ Observations on the healing of large central corneal abrasions in humans have also shown centripetal migration of three or more sheets of epithelium with convex leading edges. These arise from the remaining intact peripheral epithelium and continue to extend centrally until they meet along 'Y-shaped contact lines' to close the defect. ${ }^{29}$

Dua and Forrester ${ }^{30}$ studied human corneal epithelial defects with limbal involvement and clearly demonstrated that a preferential circumferential migration of a population of cells occurs along the limbus, from both ends of the limbal defect. This circumferential migration continues until the advancing ends meet to re-establish epithelial cover for the limbus. They also observed that complete epithelial cover for the corneal surface was not established until limbal reepithelisation was first completed. They postulated that the circumferentially migrating population of cells probably represented, in part, the healing response of limbal SC.

In patients with limbal abnormalities not related to trauma, alternating columns of normal and fluoresceinstaining cells have been noted to extend from the limbus towards the centre in radial or curvilinear rows. The columnar arrangement (columnar keratopathy) can, in some patients, be seen to correspond with the limbal palisades. A similar 'streaming' of fluorescein-stained cells in columns has also been observed in relation to broken sutures following corneal grafting. ${ }^{31}$ These observations lend support to the belief that SC activity does not occur contiguously along the limbus but rather in an interrupted manner presumably corresponding to repositories of SC in the rete ridges that alternate with palisades, which may not hold a similar mass of SC.

\section{Laboratory evidence for limbal location of putative corneal epithelial SC}

Using $\left[{ }^{3} \mathrm{H}\right]$ thymidine labeling, it has been shown that cell mitosis is highest at the corneal periphery/limbus under basal conditions, ${ }^{32,33}$ as well as after stimulation by a tumour promoter. ${ }^{34} \mathrm{~A}$ comparison of peripheral and central epithelial cells in culture has demonstrated that limbal epithelium grows faster and better than peripheral epithelium, which in turn grows better than central epithelium. ${ }^{35-37}$

More direct evidence identifying a unique population of cells at the limbus comes from other studies. ${ }^{38-41}$

Schermer et al demonstrated in rabbits that a $64 \mathrm{~K}$ keratin was not found in the basal cells at the limbus but was present in suprabasal limbal cells and in all cells of the central cornea. They hypothesised that cells lacking the $64 \mathrm{~K}$ keratin were the less differentiated SC and that their daughter cells acquired this keratin as they differentiated and matured.

Bukusoglu and Zieske have developed a monoclonal antibody that specifically binds to a $50 \mathrm{~K}$ protein localised 
Table 1 Cytochemical differences between epithelial cells of the limbal and central corneal epithelium; most of the limbal attributes apply to the basal cells

\begin{tabular}{ll}
\hline Limbus & Central cornea \\
\hline CK 5/14 +ve & CK 5/14 -ve \\
CK 3/12 -ve & CK 3/12 +ve \\
CK $19+$ ve & CK 19-ve \\
p63 +ve & p63 -ve but see the \\
& results in this paper \\
CX $43-v e$ & CX 43 +ve \\
Vimentin +ve & Vimentin -ve \\
Intrinsic melanogenesis & \\
Cytochrome oxidase and & \\
ATpase +ve & \\
Alpha enolase +ve & Alpha enolase +ve \\
Beta-1 integrin +ve & Beta-1 integrin +ve \\
EGFR +ve (strong) & EGFR +ve \\
\hline
\end{tabular}

CK: cytokeratin; CX: connexin; EGFR: epithelial growth factor receptor.

to basal limbal cells in both rat and human corneas. ${ }^{41}$ They speculate that this antibody may specifically identify corneal SC; this antibody was later identified as alpha enolase. ${ }^{42}$ They also demonstrated that all basal cells of developing rat cornea stained positive for alpha enolase antibody but gradually became sequestered to the limbal area after 2 weeks and were found exclusively in limbal basal cells by $4-6$ weeks. ${ }^{43}$ Chung et a ${ }^{44}$ extended these observations to show that the number of cells staining positive with this antibody increased after corneal wounding in rabbits.

Basic research has identified several other attributes that are unique to the limbal epithelium (Table 1); for example, EGF receptors, ${ }^{45,46}$ pigment, ${ }^{17}$ cytokeratin profile (CK3/12 negative), ${ }^{38,47}$ presence of vimentin, ${ }^{48}$ CK19, and specific basement membrane characteristics. ${ }^{49-51}$ Vimentin and CK19-positive, CK3negative clusters of cells with unique electron microscopic morphology have been demonstrated. ${ }^{52,53}$ Connexin 43 (Cx43), a gap junction protein, has been noted in human corneal but not limbal basal epithelium. ${ }^{54-56}$ It has been proposed that acquisition of Cx43 denotes differentiation into TAC and that absence of Cx43 could endow limbal SC with the property of stemness in their microenvironmental niche, segregating them from neighbouring cells and therefore less vulnerable to adverse influences from them. ${ }^{56} \mathrm{p} 63$, a transcriptional factor involved in morphogenesis, has been proposed to identify keratinocyte SC at the limbus. ${ }^{57}$ Zhao et al ${ }^{58}$ have recently reported that limbal epithelial cells cultured in the presence of mitogens express neural progenitor markers, specifically nestin. They suggested that the adult corneal epithelium may serve as a model for characterising neural potential of heterologous SC or progenitors.

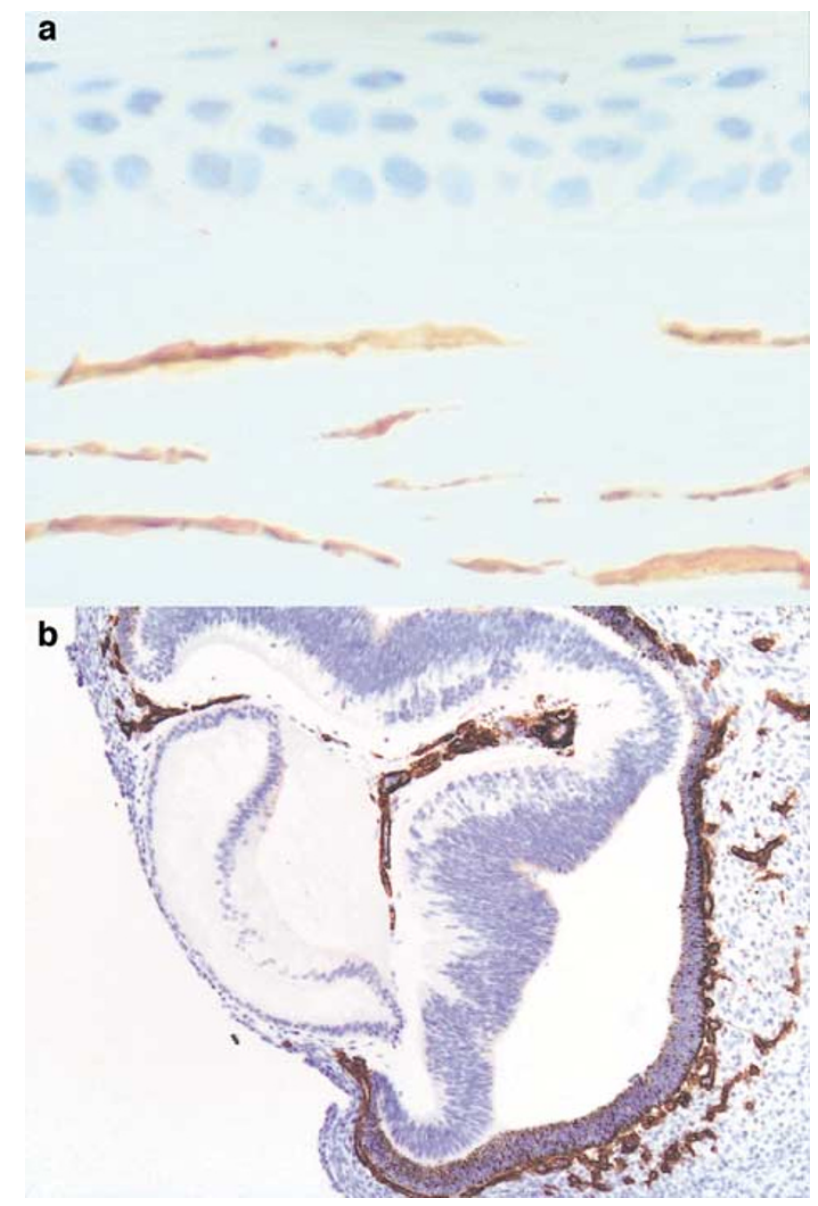

Figure 1 CD34 expression: (a) Photomicrograph of human adult cornea showing expression of CD34 on corneal stromal keratocytes but not on the epithelium (DAB; original magnification $\times 400$ ). (b) Photomicrograph of embryonic eye demonstrating absence of staining of the cornea with CD34 (DAB; original magnification $\times 400$ )

We have investigated the possibility of using the haematopoietic SC markers CD34 and CD133 to mark the corneal epithelial SC. CD34 is a heavily glycosylated type I transmembrane protein expressed on early lymphohaematopoietic stem and progenitor cells, small vessel endothelial cells, embryonic fibroblasts, and fibroblastlike dendritic cells in connective tissues. Three distinct epitopes, determined by enzyme sensitivity to neuraminidase (NA), chymopapain (CP), and a glycoprotease (GP), have been identified on CD34. The monoclonal antibodies reacting against these epitopes are designated Class I (sensitive to NA, CP, and GP), Class II (sensitive to CP and GP but not NA), and Class III (insensitive to NA, CP, and GP). CD133 is a glycoprotein that was first detected on CD34 bright haematopoietic SC. ${ }^{59}$ It is also known to be expressed on haemangioblasts, retinoblastoma, neural SC and 

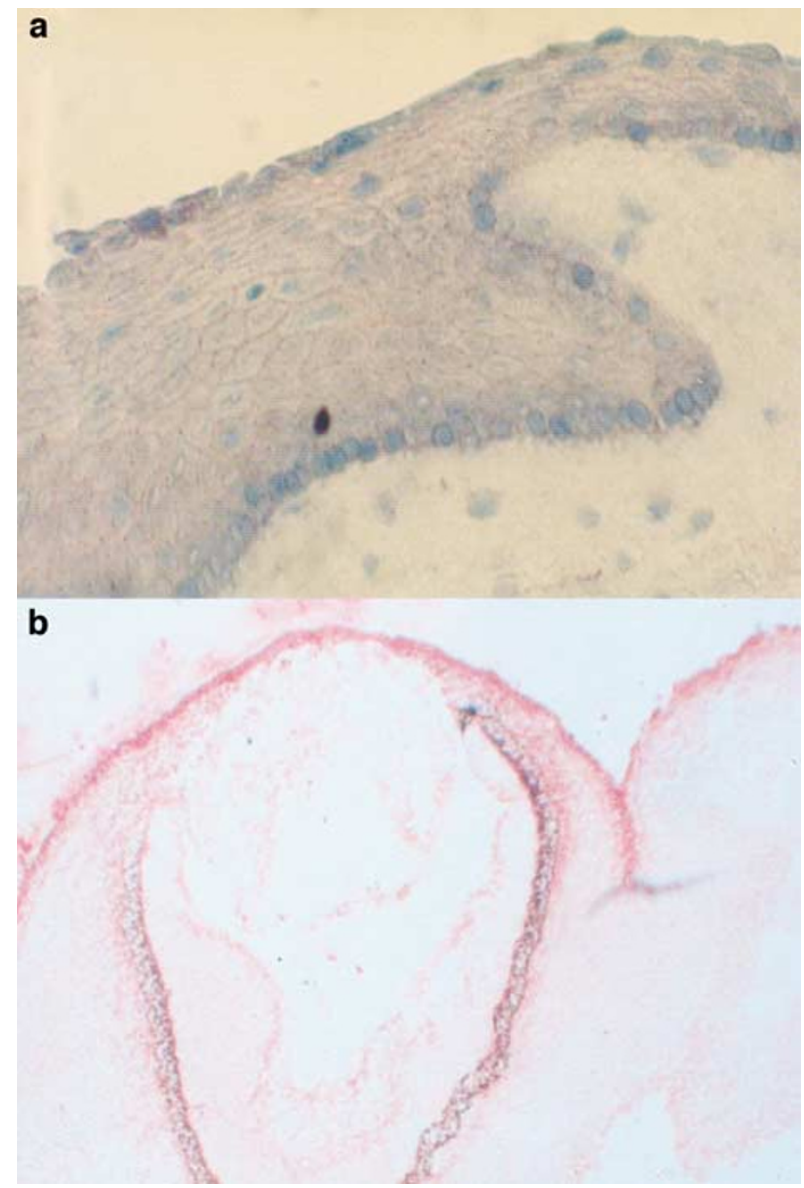

Figure 2 CD133 expression (a) Photomicrograph of human adult cornea showing uniform membranous expression of CD133 by all the epithelial cells (alkaline phosphatase antialkaline phosphatase (APAP); original magnification $\times 400$ ). (b) Photomicrograph of embryonic eye demonstrating uniform staining of both layers of the cornea with CD133 (APAP; original magnification $\times 100$ ).

developing epithelium. The CD133 antigen has not yet been demonstrated on adult epithelial tissue.

A characteristic feature of this protein is its rapid downregulation during cell differentiation. Yu et al ${ }^{60}$ have shown that CD133-2 is coexpressed with beta 1 integrins on $10 \%$ of neonatal foreskin epidermis, with loss of expression as the cells differentiated in culture. Therefore, they reported that CD133-2 serves as a marker for undifferentiated cells.

We found that CD34 is strongly expressed by human corneal keratocytes (Figure 1a) but not by the corneal epithelium or endothelium (in communication). There was also no expression of CD34 in the bilayered corneal epithelium of 6- to 8-week-old embryos (Figure 1b), thereby ruling out the possibility that CD34 is a marker of corneal epithelial SC. In contrast to our findings with CD34, expression of CD133-2 was seen in all the layers of
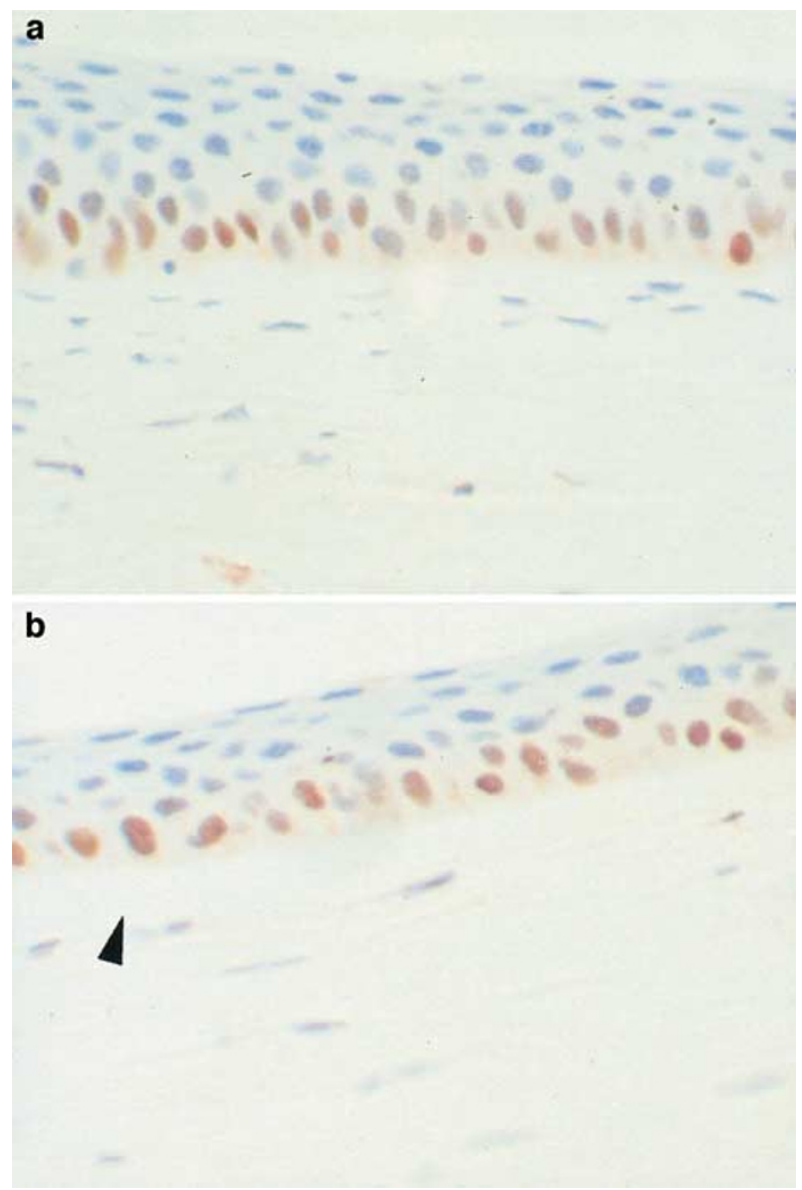

Figure 3 p63 expression. (a) Photomicrograph of human adult cornea showing expression of p63 by the basal cells of the corneoscleral limbus and (b) similar expression of p63 by the basal cells of the central cornea; note the clear Bowman's zone (arrow) between the epithelium and stroma of the central cornea $(\mathrm{DAB}$; original magnification $\times 400)$.

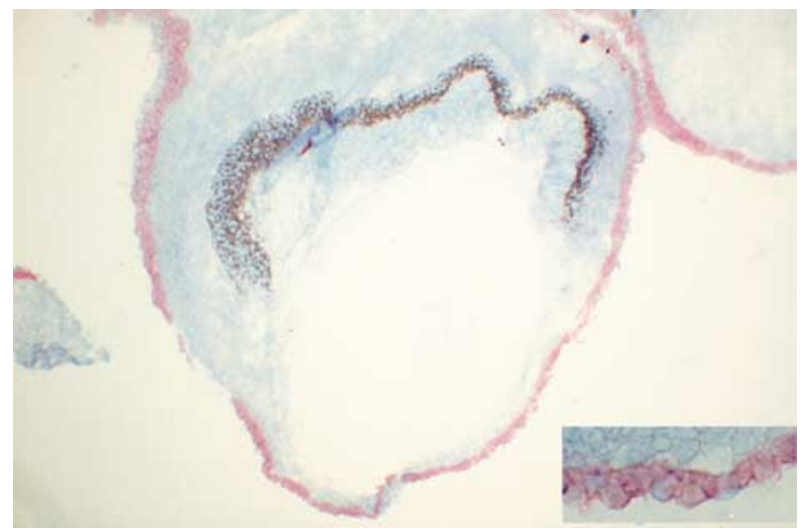

Figure 4 Foetal p63. Photomicrograph of embryonic eye demonstrating expression of p63 by the corneal epithelial cells (APAP; original magnification $\times 100$ ). Inset shows magnified view of the bilayered positively staining embryonic corneal epithelium $(\times 400)$. 
limbal and corneal epithelium in normal human adult cornea (Figure 2a). The CD133 staining was membranous and uniformly present in all the cells. CD133 expression was also seen in both layers of the corneal epithelium of 6- to 8-week-old embryos (Figure 2b).

p63 has recently been identified as a corneal epithelial SC marker by Pellegrini et al. ${ }^{57}$ They reported its presence in limbal basal epithelial cells only. We performed immunohistochemistry using p63 on frozen sections of normal adult human cornea and found that there was positive staining for p63 among most of the basal cells of the central as well as limbal corneal epithelium. This finding was confirmed by using the same p63 antibody, with appropriate antigen retrieval techniques, on formalin-fixed normal adult human corneal specimens (Figure 3a and b). p63 expression was also positive in all the cells of the two-layered corneal epithelium of 6- to 8-week-old embryos (Figure 4). These findings suggest that P63 is too ubiquitous to be an SC marker. Its presence in the basal epithelium of the central cornea would also refute the suggestion that it is a limbal SC marker. It is quite possible that limbal SC express p63 but so do almost all other basal cells of the limbus and cornea.

From the data available to date from both clinical and laboratory studies, it appears that a 'Source cell' does exist at the corneo-scleral limbus. Whether this is truly an SC, in the context of the definition of an SC for the haemotopoietic system and intestinal epithelium for example, remains uncertain. In the absence of any marker for the direct identification of limbal SC and lack of evidence on any lineage differentiation it may have, limbal SC at best can be described as unipotent SC. Some might even question the use of the term SC and prefer the term 'committed progenitors' instead.

\section{Effects of deficiency}

The hallmark of limbal SC deficiency is 'conjunctivalisation' of the cornea, and the most significant clinical manifestation is a persistent corneal epithelial defect. The clinical symptoms of limbal deficiency may include decreased vision, photophobia, tearing, blepharospasm, and recurrent episodes of pain (epithelial breakdown), as well as a history of chronic inflammation with redness.

Depending on the extent of limbal involvement, SC deficiency can be partial or total. Partial SC deficiency may vary in extent to involve the pupillary area, when intervention is usually required, or exclude the visual axis, when none or minimal intervention with topical medication may be required. Further, partial SC deficiency may vary in severity from mild, when only an abnormal epithelial sheet covers a variable area of the

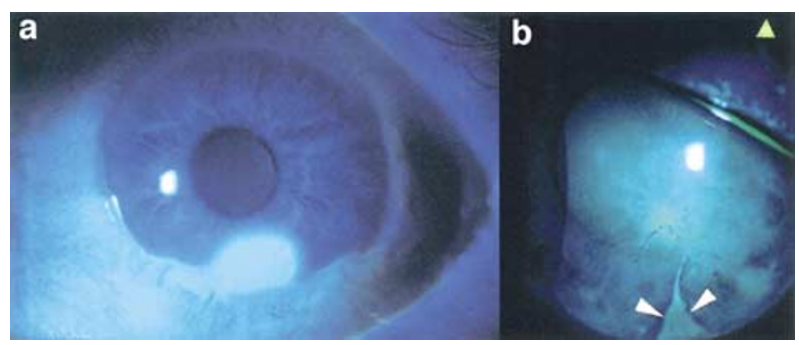

Figure 5 (a) Mild limbal SC deficiency with loss of limbal anatomy and an associated persistent epithelial defect. (b) A wedge of conjunctival epithelium has covered a small area of limbus (arrows) and stains with fluorescein.

cornea, to severe when a part of the cornea, usually including the pupillary area, is covered by a thick fibrovascular pannus.

The clinical features of SC deficiency, from mild to severe, include the following: ${ }^{19,30,31,61-65}$ (a) loss of limbal anatomy; (b) irregular, thin epithelium; (c) stippled fluorescein staining of the area covered by abnormal epithelium; (d) unstable tear film; (e) filaments and erosions; (f) superficial and deep vascularisation; (g) persistent epithelial defects leading to ulceration, melting, and perforation, (h) fibrovascular pannus; and (i) scarring, keratinisation, and calcification.

Loss of limbal anatomy: The normal limbal architecture with rows of palisades and the perilimbal vascular arcade is usually best defined at the superior and inferior limbus. The definition of palisades is less distinct nasally and temporally. Subtle changes such as staining of conjunctiva-derived cells on and across the limbus (Figure 5a and b), which may be associated with a persistent epithelial defect (Figure 5a) and other changes such as scarring, vascularisation, or limbal hyperaemia indicating chronic inflammation, can be seen in the early stages.

Irregular, thin epithelium: When the initial injury is mild and superficial or the disease process leading to SC deficiency is slowly progressive, loss of a segment of limbal epithelium may occur without significant damage to the substratum. A sheet of conjunctival/metaplastic epithelium consequently covers the cornea without any notable vascularisation. This epithelium is usually thin and irregular as can be seen by the pooling of fluorescein dye at the junction of the abnormal and remaining normal epithelium (Figure 6a). ${ }^{63}$

Stippled fluorescein staining of the area covered by abnormal epithelium: The abnormal conjunctival/metaplastic epithelium readily takes up fluorescein dye ${ }^{66}$ allowing easy visualisation of the abnormal cells and their pattern of distribution. The abnormal fluorescein-staining 'conjunctivalised' epithelium may take on the pattern of 


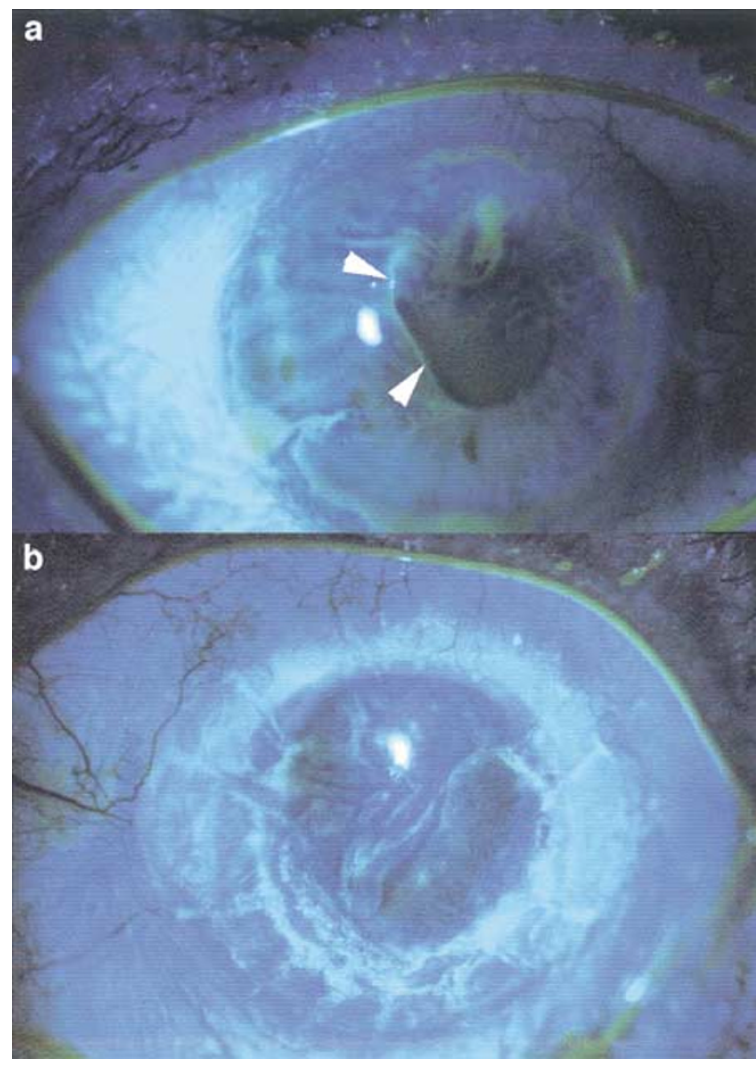

Figure 6 (a) Mild partial limbal SC deficiency following a chemical burn. The visual axis is covered by surviving healthy corneal epithelium, which is demarcated by a line of fluorescein pooling (arrows) from the staining thinner conjunctiva-derived epithelium. (b) Swirls and whorls of staining epithelium on a corneal graft performed in a patient with limbal SC deficiency. The visual axis is involved.

columns, whorls, or wedges with the broad base towards the limbus and the narrow curving apex towards the corneal centre (Figure $6 \mathrm{~b}) .^{31}$

Unstable tear film: The abnormal epithelium demonstrates a rapid tear film break-up time over it, and areas of negative and positive fluorescein staining can be seen.

Filaments and erosions: Tags of loose epithelium,

filaments with mucus and recurrent erosions are other features associated with the abnormal epithelial cover on the cornea.

Superficial and deep vascularisation: In moderate to severe cases of SC deficiency, superficial and/or deep vascularisation of the cornea occurs (Figure $7 a$ and $b$ ). Initially it is restricted to the segment of SC deficiency but in later stages the entire circumference may become involved (Figure 7c).

Persistent epithelial defects: (Figure 8a) Chronic nonhealing ulceration of the corneal epithelium or cycles of repeated breakdown followed by healing, associated

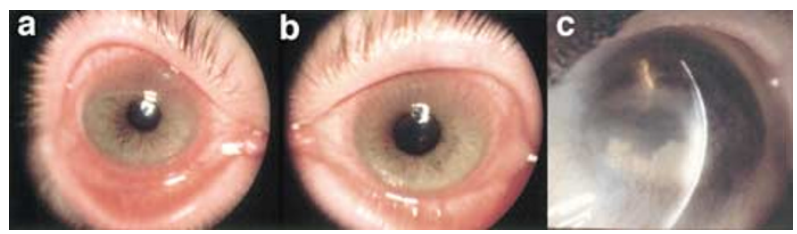

Figure $7 \quad(a, b)$ Right and left eyes of a patient with partial limbal SC deficiency following prolonged contact lens wear. Superficial vascularisation has affected almost the upper half of each eye. (c) Superficial and deep vascularisation with an area of scarring following an alkali injury leading to partial limbal SC deficiency.

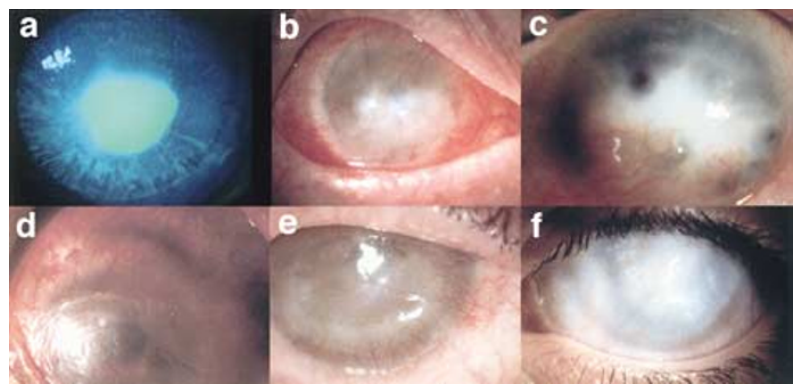

Figure 8 (a) A persistent epithelial defect after cement (alkali) injury. (b) Severe total SC deficiency with $360^{\circ}$ vascularisation and scarring. (c) Total SC deficiency with vascularisation, scarring, and thinning of the cornea. (d) Total severe SC deficiency associated with drying, leading to keratinisation of the entire ocular surface. (e) Total SC deficiency with scarring and inferior melting. (f) Total SC deficiency in a patient with aniridia showing scarring and calcification.

with a chronic low-grade inflammation, is a feature of limbal SC deficiency. These defects are liable to lead to deep stromal infiltrates that may or may not be related to infection. The edges of the epithelial defect have a distinct rolled-up or heaped appearance. Over time, progressive melting of the corneal stroma with perforation can occur.

Fibrovascular pannus: In moderate to severe cases of SC deficiency, epithelial cover of the denuded cornea is associated with encroachment of fibrovascular tissue of varying thickness (Figure $8 \mathrm{~b}$ and c). ${ }^{67}$ This tissue supports the thickened multilayered conjunctiva-derived epithelium.

Scarring, keratinisation, and calcification: (Figure 8b-f) The end stage of the aftermath of limbal SC deficiency, what ever the cause, is scarring and eventually calcification of the affected tissue. Usually by this stage, the inflammation has subsided and the eye is comparatively comfortable. In patients who have associated severe dry eyes, the covering epithelium becomes totally or partially keratinised (Figure 8d).

The presence of goblet cells on an impression cytology specimen taken from the corneal surface or in a biopsy 


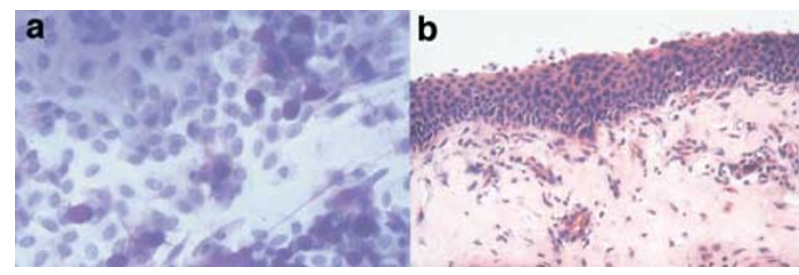

Figure 9 (a) Impession cytology taken from the cornea of a patient with total SC deficiency. Goblet cells (reddish pink staining) are clearly visible, indicating conjunctivalisation (PAS $\times 400$ ). (b) Histology of a punch biopsy of the fibrovascular panus in a patient with total limbal SC deficiency. Multilayered epithelium on a vascularised stroma $(\mathrm{H} \& \mathrm{E} \times 200)$.

specimen of the fibrovascular pannus covering the cornea is pathognomonic of conjunctivalisation of the cornea (Figure 9a) ${ }^{68}$ Biopsy specimens also demonstrate a multilayered, at times keratinised, epithelium overlying dense fibrous and vascular tissue (Figure 9b). Intraepithelial lymphocytes, which are a feature of conjunctival epithelium, are also seen on conjunctivalised corneal epithelium. These are predominantly CD8 + / ${ }^{*} \mathrm{HML}-1+$ cells (*cytotoxic T lymphocytes expressing the human mucosal lymphocyte antigen). Features of squamous metaplasia or loss of cornea-specific cytokeratins (CK 3/12) on immunohistology are other effects noted on biopsy specimens.

\section{Acknowledgement}

Vijay A Shanmuganthan is supported by the Alexander Pigott Wernher Memorial Trust.

\section{References}

1 Fuchs E, Segre JA. Stem cells: a new lease on life. Cell 2000; 100: 143-155.

2 Alison MR, Poulsom R, Forbes S, Wright NA. An introduction to stem cells. J Pathol 2002; 197: 419-423.

3 Janes SM, Lowell S, Hutter C. Epidermal stem cells. J Pathol 2002; 197: 479-491.

4 Poulsom R, Alison MR, Forbes SJ, Wright NA. Adult stem cell plasticity. J Pathol 2002; 197:441-456.

5 Bishop AE, Buttery LD, Polak JM. Embryonic stem cells. J Pathol 2002; 197: 424-429.

6 Mills JC, Gordon JI. The intestinal stem cell niche: there grows the neighborhood. Proc Natl Acad Sci USA 2001; 98: 12334-12336.

7 Krause DS, Fackler MJ, Civin CI, May WS. CD34: structure, biology, and clinical utility. Blood 1996; 87: 1-13.

8 Hossain PNJ, Joseph S, Powell-Richards A. Dua H.S. Human keratocytes express high levels of CD34 in situ (ARVO abstract). Invest Ophthalmol Vis Sci 2001; 42(4)S1-945: B230 (Abstract 3088).

9 Bhatia M. AC133 expression in human stem cells. Leukemia 2001; 15: 1685-1688.
10 Corbeil D, Roper K, Hellwig A, Tavian M, Miraglia S, Watt SM et al. The human AC 133 hematopoietic stem cell antigen is also expressed in epithelial cells and targeted to plasma membrane protrusions. J Biol Chem 2000; 275: 5512-5520.

11 Jones PH, Watt FM. Separation of human epidermal stem cells from transit amplifying cells on the basis of differences in integrin function and expression. Cell 1993; 73: 713-724.

12 Rietze RL, Valcanis H, Brooker GF, Thomas T, Voss AK, Bartlett PF. Purification of a pluripotent neural stem cell from the adult mouse brain. Nature 2001; 412: 736-739.

13 Kaneko Y, Sakakibara S, Imai T, Suzuki A, Nakamura Y, Sawamoto K et al. Musashil: an evolutionally conserved marker for CNS progenitor cells including neural stem cells. Dev Neurosci 2000; 22: 139-153.

14 Brittan M, Wright NA. Gastrointestinal stem cells. J Pathol 2002; 197: 492-509.

15 Wolf NS, Kone A, Priestley GV, Bartelmez SH. In vivo and in vitro characterization of long-term repopulating primitive hematopoietic cells isolated by sequential Hoechst 33342rhodamine 123 FACS selection. Exp Hematol 1993; 21: 614-622.

16 Thoft RA, Friend J. The X, Y, Z hypothesis of corneal epithelial maintenance. Invest Ophthalmol Vis Sci 1983; 24: 1442-1443.

17 Davanger M, Evensen A. Role of the pericorneal papillary structure in renewal of corneal epithelium. Nature 1971; 229: 560-561.

18 Townsend WM. The limbal palisades of Vogt. Trans Am Ophthalmol Soc 1991; 89: 721-756.

19 Tseng SC. Concept and application of limbal stem cells. Eye 1989; 3(Part 2): 141-157.

20 Mann I. A study of epithelial regeneration in the living eye. Br J Ophthalmol 1944; 28: 26-40.

21 Buschke WH. Morphologic changes in cells of corneal epithelium in wound healing. Arch Ophthalmol 1949; 41: 306-316.

22 Kaye DB. Epithelial response in penetrating keratoplasty. Am J Ophthalmol 1980; 89: 381-387.

23 Kinoshita S, Friend J, Thoft RA. Sex chromatin of donor corneal epithelium in rabbits. Invest Ophthalmol Vis Sci 1981; 21: 434-441.

24 Buck RC. Cell migration in repair of mouse corneal epithelium. Invest Ophthalmol Vis Sci 1979; 18: 767-784.

25 Buck RC. Measurement of centripetal migration of normal corneal epithelial cells in the mouse. Invest Ophthalmol Vis Sci 1985; 26: 1296-1299.

26 Goldberg MF, Bron AJ. Limbal palisades of Vogt. Trans Am Ophthalmol Soc 1982; 80: 155-171.

27 Matsuda M, Ubels JL, Edelhauser HF. A larger corneal epithelial wound closes at a faster rate. Invest Ophthalmol Vis Sci 1985; 26: 897-900.

28 Srinivasan BD, Eakins KE. The reepithelialization of rabbit cornea following single and multiple denudation. Exp Eye Res 1979; 29: 595-600.

29 Dua HS, Forrester JV. Clinical patterns of corneal epithelial wound healing. Am J Ophthalmol 1987; 104: 481-489.

30 Dua HS, Forrester JV. The corneoscleral limbus in human corneal epithelial wound healing. Am J Ophthalmol 1990; 110: 646-656.

31 Dua HS, Gomes JA, Singh A. Corneal epithelial wound healing. Br J Ophthalmol 1994; 78: 401-408.

32 Friedenwald JSB, Buschke W. Some factors concerned in the mitotic and wound-healing activities of the 
corneal epithelium. Trans Am Ophthalmol Soc 1944; 42. 371-383.

33 Hanna COBJ. Cell production and migration in the epithelial layer of the cornea. Arch Ophthalmol 1960; 64: 536-539.

34 Cotsarelis G, Cheng SZ, Dong G, Sun TT, Lavker RM. Existence of slow-cycling limbal epithelial basal cells that can be preferentially stimulated to proliferate: implications on epithelial stem cells. Cell 1989; 57: 201-209.

35 Ebato B, Friend J, Thoft RA. Comparison of central and peripheral human corneal epithelium in tissue culture. Invest Ophthalmol Vis Sci 1987; 28: 1450-1456.

36 Ebato B, Friend J, Thoft RA. Comparison of limbal and peripheral human corneal epithelium in tissue culture. Invest Ophthalmol Vis Sci 1988; 29: 1533-1537.

37 Eggli P, Boulton M, Marshall J. Growth characteristics of central and peripheral bovine corneal epithelial cells in vitro. Graefes Arch Clin Exp Ophthalmol 1989; 227: 263-270.

38 Schermer A, Galvin S, Sun TT. Differentiation-related expression of a major $64 \mathrm{~K}$ corneal keratin in vivo and in culture suggests limbal location of corneal epithelial stem cells. J Cell Biol 1986; 103: 49-62.

39 Lavker RM, Dong G, Cheng SZ, Kudoh K, Cotsarelis G, Sun TT. Relative proliferative rates of limbal and corneal epithelia. Implications of corneal epithelial migration, circadian, rhythm and suprabasally located DNAsynthesizing keratinocytes. Invest Ophthalmol Vis Sci 1991; 32: 1864-1875.

40 Dua HS, Azuara-Blanco A. Limbal stem cells of the corneal epithelium. Surv Ophthalmol 2000; 44: 415-425.

41 Zieske JD, Bukusoglu G, Yankauckas MA. Characterization of a potential marker of corneal epithelial stem cells. Invest Ophthalmol Vis Sci 1992; 33: 143-152.

42 Zieske JD, Bukusoglu G, Yankauckas MA, Wasson ME, Keutmann HT. Alpha-enolase is restricted to basal cells of stratified squamous epithelium. Dev Biol 1992; 151: 18-26.

43 Chung EH, Bukusoglu G, Zieske JD. Localization of corneal epithelial stem cells in the developing rat. Invest Ophthalmol Vis Sci 1992; 33: 2199-2206.

44 Chung EH, DeGregorio PG, Wasson M, Zieske JD. Epithelial regeneration after limbus-to-limbus debridement. Expression of alpha-enolase in stem and transient amplifying cells. Invest Ophthalmol Vis Sci 1995; 36: 13361343.

45 Zieske JD. Perpetuation of stem cells in the eye. Eye 1994; 8(Part 2): 163-169.

46 Zieske JD, Wasson M. Regional variation in distribution of EGF receptor in developing and adult corneal epithelium. J Cell Sci 1993; 106(Part 1): 145-152.

47 Cooper D, Schermer A, Sun TT. Classification of human epithelia and their neoplasms using monoclonal antibodies to keratins: strategies, applications, and limitations. Lab Invest 1985; 52: 243-256.

48 Lauweryns B, van den Oord JJ, Volpes R, Foets B, Missotten $\mathrm{L}$. Distribution of very late activation integrins in the human cornea. An immunohistochemical study using monoclonal antibodies. Invest Ophthalmol Vis Sci 1991; 32: 2079-2085.

49 Thoft RA, Wiley LA, Sundarraj N. The multipotential cells of the limbus. Eye 1989; 3(Part 2): 109-113.
50 Gipson IK, Grill SM, Spurr SJ, Brennan SJ. Hemidesmosome formation in vitro. J Cell Biol 1983; 97: 849-857.

51 Gipson IK, Kiorpes TC. Epithelial sheet movement: protein and glycoprotein synthesis. Dev Biol 1982; 92: 259-262.

52 Lauweryns B, van den Oord JJ, Missotten L. The transitional zone between limbus and peripheral cornea. An immunohistochemical study. Invest Ophthalmol Vis Sci 1993; 34: 1991-1999.

53 Lauweryns B, van den Oord JJ, De Vos R, Missotten L. A new epithelial cell type in the human cornea. Invest Ophthalmol Vis Sci 1993; 34: 1983-1990.

54 Matic M, Petrov IN, Chen S, Wang C, Dimitrijevich SD, Wolosin JM. Stem cells of the corneal epithelium lack connexins and metabolite transfer capacity. Differentiation 1997; 61: 251-260.

55 Dong Y, Roos M, Gruijters T, Donaldson P, Bullivant S, Beyer E et al. Differential expression of two gap junction proteins in corneal epithelium. Eur J Cell Biol 1994; 64: 95-100.

56 Wolosin JM, Xiong X, Schutte M, Stegman Z, Tieng A. Stem cells and differentiation stages in the limbo-corneal epithelium. Prog Retin Eye Res 2000; 19: 223-255.

57 Pellegrini G, Dellambra E, Golisano O, Martinelli E, Fantozzi I, Bondanza $\mathrm{S}$ et al. p63 identifies keratinocyte stem cells. Proc Natl Acad Sci USA 2001; 98: 3156-3161.

58 Zhao X, Das AV, Thoreson WB, James J, Wattnem TE, Rodriguez-Sierra J et al. Adult corneal limbal epithelium: a model for studying neural potential of non-neural stem cells/progenitors. Dev Biol 2002; 250: 317-331.

59 Yin AH, Miraglia S, Zanjani ED, Almeida-Porada G, Ogawa M, Leary AG et al. AC133, a novel marker for human hematopoietic stem and progenitor cells. Blood 1997; 90: 5002-5012.

60 Yu Y, Flint A, Dvorin EL, Bischoff J. AC133-2, a novel isoform of human AC133 stem cell antigen. J Biol Chem 2002; 277: 20711-20716.

61 Dua HS. Stem cells of the ocular surface: scientific principles and clinical applications. Br J Ophthalmol 1995; 79: 968-969.

62 Dua HS, Azuara-Blanco A. Allo-limbal transplantation in patients with limbal stem cell deficiency. Br J Ophthalmol 1999; 83: 414-419.

63 Dua HS. The conjunctiva in corneal epithelial wound healing. Br J Ophthalmol 1998; 82: 1407-1411.

64 Dua HS, Saini JS, Azuara-Blanco A, Gupta P. Limbal stem cell deficiency: concept, aetiology, clinical presentation, diagnosis and management. Indian J Ophthalmol 2000; 48: 83-92.

65 Pfister RR. Corneal stem cell disease: concepts, categorization, and treatment by auto- and homotransplantation of limbal stem cells. Clao J 1994; 20: 64-72.

66 Huang AJ, Tseng SC. Corneal epithelial wound healing in the absence of limbal epithelium. Invest Ophthalmol Vis Sci 1991; 32: 96-105.

67 Kenyon KR, Tseng SC. Limbal autograft transplantation for ocular surface disorders. Ophthalmology 1989; 96: 709-722; discussion 722-723.

68 Puangsricharern V, Tseng SC. Cytologic evidence of corneal diseases with limbal stem cell deficiency. Ophthalmology 1995; 102: 1476-1485. 